\title{
FLORA E VEGETAÇÃO DO BRASIL NA CARTA DE CAMINHA
}

\author{
Tarciso S. Filgueiras ${ }^{13}$ \\ Ariane Luna Peixoto ${ }^{2} 3$
}

Recebido em 26/03/2001. Aceito em 18/12/2001.

\begin{abstract}
RESUMO - (Flora e vegetação do Brasil na Carta de Caminha). Apresenta-se uma análise dos termos referentes a plantas e a vegetação encontrados na Carta de Pero Vaz de Caminha ao Rei D. Manoel, quando do descobrimento do Brasil ("Carta a El Rei D. Manoel"). Tomou-se como ponto de partida a versão da Carta publicada por Rubem Braga. Nesse texto, foram numeradas todas as linhas (1 a 1013) que em seguida foram examinadas minuciosamente, a procura de referências diretas ou indiretas a plantas ou suas associações. A carta de Caminha apresenta 118 menções a plantas ou associações de plantas. Desse total, 18 termos são repetidos de duas a 22 vezes. Descontadas as repetições, são mencionadas 45 termos botânicos, 31 diretos (ex.: "ervas", "lenha", "inhame") e 14 indiretos (ex. :"arco", "rede", "cruz"). Dois termos referem-se a fitofisionomias ("mata", "arvoredo (s)") e 43 a plantas ou partes delas. As 31 referências diretas reduzem-se a 29 já que as expressões "ervas compridas" e "botelho" descrevem à mesma planta, como também "ouriços verdes" e "grãos vermelhos". Das referências diretas, cinco ("arroz", "castanheiro", "figos", "legumes", "trigo") descrevem plantas exóticas, basicamente européias, as demais (24 referências), dizem respeito à flora nativa. Dentre as 14 citações indiretas, duas ("pão", "vinho") referem-se a plantas do Velho Mundo, 12 seriam nativas. Dessas, apenas duas ("tintura vermelha", "tintura preta") podem ser associadas com espécies identificáveis. Os termos referentes a plantas foram ordenados nas categorias: 1. Não identificáveis (ex.: "lenha", "pau”, "sementes"); 2. Identificáveis a nível de família (ex.: "palmeira", "cana”); possivelmente identificáveis a nível genérico (ex.: "ervas compridas", "inhame”, "fetos”); espécies de identificação segura ("ouriços verdes", "grãos vermelhos"). Os primeiros recursos vegetais explorados pelos portugueses foram "lenha" e "palmitos". O texto de Caminha não confirma a presença de uma cruz durante a celebração da Primeira Missa no Brasil, como retratado na célebre pintura de Victor Meirelles. O texto afirma que a cruz foi "chantada" por ocasião da Segunda Missa.
\end{abstract}

Palavras-chave - Viagem de Pedro Álvares Cabral, descobrimento do Brasil, história da botânica

ABSTRACT - (The flora and the vegetation of Brazil in Caminha's letter, written in 1500, to the Portuguese king D. Manoel I). An analysis of the terms related to plants and vegetation types found in the letter by Pero Vaz de Caminha (scriber of the expedition) to D. Manoel I, king of Portugal ("Carta a El Rei D. Manoel) is presented. The letter, written in 1500, is an account of the voyage of the Portuguese navigator Pedro Álvares Cabral during which a new land ("Terra da Vera Cruz", now Brazil) was discovered. Because of its tremendous historical importance to

1 UPIS - Faculdades Integradas, Departamento de Agronomia, Campus II, Cx. Postal 10743, Planaltina, DF CEP 73350-980; tfilg@uol.com.br

2 Universidade Federal Rural do Rio de Janeiro, Departamento de Botânica. Cx. Postal 74582, Seropédica, RJ CEP 23851-970; alpeixoto@terra.com.br

3 Bolsista do CNPq 
Brazil, the Carta has been considered the birth certificate of the country. Each line of the text was numbered (from 1 to 1013), then each line was carefully examined for words that refer directly or indirectly to plants or plant associations. 118 such references were found, 77 of which are repeated two to 22 times. When the repetitions were subtracted, 45 botanical terms resulted, 31 direct references (ex.: "herbs," "fire wood") and 14 indirect (ex.: "bow", "arrow"). Two terms refer to vegetation types and 43 to plants or plant parts. Five direct references refer to introduced species (ex.: rice, figs), the remaining 24 refer to native species. These were divided into four categories: 1 . Terms not referable to any specific botanical name (ex.: seed, fruits) 2. Terms referable to plant families (ex.: palms, cane; families Arecaceae and Poaceae, respectively); terms referable to plant genera (ex. "ervas compridas (Sargassum), "fetos" (Alsophilla); terms referable to a botanical species ("ouriços verdes", "grãos vermelhos", i.e., Bixa orellana L.). The first plant resources extracted from the newly found land by the Portuguese explorers were fire wood and palm hearts.

Key words - Voyage of Pedro Álvares Cabral, discovery of Brazil, history of botany

\section{Introdução}

O descobrimento do Brasil está documentado em várias fontes primárias que podem ser divididas em três grupos: cartas escritas por membros da expedição de Cabral, cartas redigidas por banqueiros e mercadores que financiaram a expedição e crônicas dos historiadores oficiais do reino de Portugal (Bueno, 1998).

Para o estudo em tela, as fontes primárias do primeiro grupo, fontes presenciais, são as mais importantes. São elas: a Carta de Pero Vaz de Caminha, a do Mestre João Faras e a "Relação do Piloto Anônimo". Simões (1999) apresenta estes três documentos em três versões: facsímile do texto manuscrito, leitura paleográfica e leitura atualizada. Dentre eles, o primeiro é, sem sombra de dúvida, o que mais informação traz sobre as plantas, seus usos e associações. Ruben Braga, na introdução à versão moderna da Carta de Caminha a chamou de "venerável documento" e "certidão de batismo" do Brasil. A Carta de Mestre João embora relate o descobrimento, não faz menção alguma a plantas. Já o autor da "Relação" diz, no capítulo I, que quando os descobridores se chegaram à nova terra para $\mathrm{a}$ reconhecer, acharam-na "muito povoada de árvores". Este documento faz outras menções a plantas que serão discutidas ao longo do texto.

A Carta de Caminha e a do Mestre João Faras foram dirigidas ao Rei D. Manoel I, cognominado "O Venturoso", que governou Portugal entre 1495 e 1521, período áureo das descobertas marítimas. Durante o reinado de D. Manoel I, Vasco da Gama fez a primeira viagem entre Europa e Ásia e Pedro Álvares Cabral, a primeira viagem aos quatro continentes (Pereira, 1999). A "Relação do Piloto Anônimo" foi escrita em forma de diário por autor que preferiu o anonimato em troca do pagamento para narrar a viagem da armada de 1500 . O texto, escrito originalmente em Português, foi posteriormente vertido para o italiano e se perdeu. A versão italiana foi publicada, entretanto, quando Pedro Álvares Cabral ainda vivia, sendo o texto que se conhece em português uma tradução da versão italiana.

O bacharel João Faras, médico e cirugião (Johanes artium et medicine bachalarius), realizou e relatou em sua carta as primeiras observações astronômicas em terras brasileiras. Fez um esboço descritivo da constelação do Cruzeiro do Sul e de outras estrelas visíveis no hemisfério sul ("e estas estrellas, prinçipalmente las de la cruz, son grandes, casy como las del carro; e la estrella del polo antartyco, o sul, es pequena, como la del norte, e muy clara; e la estrella que esta en rriba de toda la crus es mucho pequena"(Cortesão, 1994).

Outro documento histórico contemporâneo das Cartas mencionadas é outra Carta, a de D. Manoel I aos Reis Católicos. Nela sua majestade menciona o significativo fato de que Cabral 
havia descoberto uma terra "á la cual puso nombre de Santa Cruz". O Venturoso não mencionou plantas em sua missiva.

A Carta de Caminha foi explorada por diferentes autores, especialmente por historiadores. Pereira (1999) apresenta extensa revisão bibliográfica sobre o tema. Especificamente do ponto de vista botânico, foi estudada por AndradeLima (1984), que utilizando-se do texto que aparece na obra de Cortesão (1943), teceu comentários sobre a identificação botânica de vários termos utilizados por Caminha e sobre a abordagem feita pelo próprio Cortesão. AndradeLima ressaltou que as plantas foram vistas antes mesmo que a própria terra, os chamados sinais de terra, que eram "muita quantidade" ... "que os mareantes chamam botelho e também outras que também chamam de rabo-de-asno".

Muitos cientistas brasileiros e de outros países se debruçaram sobre a documentação histórica da botânica brasileira (Borgmeier, 1961; Carauta, 1967; Moulin et al., 1986; Silva, 1995; Peixoto, 1999, entre outros). Tal documentação ultrapassa o universo da botânica e da história natural, inserindo-se no contexto das artes, medicina, antropologia, e muitos outros. É especialmente vasta e preciosa a literatura e a iconografia que relatam e ilustram as viagens pelo Brasil, desde o descobrimento, mas especialmente aquelas referentes ao século XIX.

O presente trabalho teve como objetivo principal uma leitura da percepção do mundo vegetal pela frota cabralina, tomando como base a Carta de Caminha. Esta leitura reflete, basicamente, a vivência dos autores deste trabalho nas áreas de morfologia e taxonomia vegetal e a subsequiente busca, em fontes diversas, de informações que auxiliaram na atribuição de possíveis nomes botânicos aos termos empregados por Caminha.

\section{Material e métodos}

Tomou-se como ponto de partida uma versão moderna da Carta de Pero Vaz de Caminha, escrita em abril de 1500, a El Rey D. Manoel a versão de Rubem Braga (1981), ilustrada por Carybé. Nesse texto todas as linhas foram numeradas (1 a 1013). Em seguida o texto foi examinado linha por linha, a procura de referências diretas ou indiretas a plantas ou suas associações. As referências encontradas na Carta foram listadas (Tab. 1) e agrupadas nas categorias "referências diretas" e "referências indiretas" (Tab. 2) "identificáveis" (Tab. 4), "não identificáveis" (Tab. 3). Dentro das categorias referências diretas e identificáveis, foram feitas tentativas de atribuição de nomes científicos às plantas ou parte delas citadas neste documento. A atribuição de nomes botânicos baseou-se principalmente na experiência profissional dos autores do presente trabalho e também na literatura disponível sobre o tema.

Informações complementares foram retirados das Cartas de Mestre João (1 de maio de 1500), da "Relação do Piloto anónimo" (cap. I,II e III; 1500) e da "Carta del Rey D. Manoel de Portugal á los Reyes Católicos" (1500). Esses três documentos foram examinados em suas versões originais, fac-similados, bem como transcritos na obra de Cortesão (1994), Pereira (1999) e Simões (1999).

\section{Resultados e discussão}

A Carta de Caminha a D. Manoel I, rei de Portugal, menciona direta ou indiretamente plantas ou associações vegetais. São 118 menções, 77 delas repetições. Excluídas as repetições, são mencionados 45 termos referentes a plantas. Dois termos ("mata" e "arvoredo"(s) aplicamse a fitofisionomias. Os termos "ervas compridas" e "botelho" referem- se à mesma planta, um membro do reino Protoctista (sensu Margulis \& Schwartz,1999). Os demais 43 referem-se a membros do reino Plantae, As palavras "arco" (s) e "seta" (s) são mencionadas 19 e 11 vezes, respectivamente. A palavra "cruz" aparece 9 vezes, 8 como referência indireta a planta (madeira) e 
Tabela 1. Termos associados a plantas citados na Carta de Pero Vaz de Caminha (versão moderna publicada por Rubem Braga (1981)), e número da linha na qual o termo é citado.

\begin{tabular}{|c|c|c|c|c|c|}
\hline 40 & Ervas & 465 & Setas & 689 & Cruz; pau \\
\hline 41 & Botelho & 480 & Arcos & 694 & Cruz \\
\hline 42 & Outras [ervas] & 483 & Arcos; setas & 695 & Madeira; paus \\
\hline 43 & Rabo-de-asno & 494 & Tintura preta & 696 & Cunha \\
\hline 49 & Arvoredos & 502 & Pano (não sei de quê) & 697 & Tala \\
\hline 51 & Cruz (Terra de Vera) & 505 & Pano & 707 & Mata; lenha \\
\hline 102 & Lenha & 509 & Pá de almadia [remo] & 708 & Árvores \\
\hline 126 & Arco; setas & 529 & Palmas & 716 & Arvoredos \\
\hline 127 & Arcos; setas & 530 & Palmitos & 720 & Lenha \\
\hline 155 & Cera & 592 & Arcos; setas & 722 & Arcos; setas \\
\hline 156 & Cera & 699 & Rama & 724 & Canas \\
\hline 182 & Pão & 600 & Fetos & 752 & Lenha \\
\hline 183 & Figos & 607 & Arcos & 758 & Arroz \\
\hline 186 & Vinho & 611 & Arcos; folhas de papel & 759 & Vinho \\
\hline 223 & Arcos; setas & 617 & Arcos & 783 & Tintura \\
\hline 235 & Arcos; setas & 623 & Tinturas & 784 & Lenha \\
\hline 237 & Arcos & 628 & Ouriços verdes & 789 & Arvoredo \\
\hline 238 & Arcos & 629 & Árvores & 794 & Arvoredo \\
\hline 246 & Palmas (moitas de) & 630 & Castanheiros & 797 & Palmas; palmitos \\
\hline 255 & Cabaças & 631 & Grãos vermelhos & 799 & Cruz \\
\hline 265 & Arcos; setas & 633 & Tintura (muito vermelha) & 800 & Árvore \\
\hline 274 & Pau (espelho de pau) & 639 & Tintura (preta) & 831 & Inhame; árvores \\
\hline 275 & Borracha & 652 & Madeira; tábuas & 832 & Frutos; árvores \\
\hline 362 & Arcos; setas & 653 & Palha & 834 & Trigo \\
\hline 366 & Almadias & 655 & Esteios & 835 & Legumes \\
\hline 368 & Traves & 656 & Rede & 859 & Cruz \\
\hline 378 & $\mathrm{Pau}$ & 663 & Inhame & 863 & Cruz \\
\hline 384 & Arcos & 664 & Sementes & 874 & Cruz \\
\hline 389 & Arco & 678 & Lenha & 921 & Cruz \\
\hline 390 & Setas; tintura vermelha & 680 & Arcos & 948 & Pano \\
\hline 394 & Tintura & 683 & Arcos & 958 & Cruz \\
\hline 400 & Cabaças & 685 & Lenha & 973 & Arvoredo \\
\hline 456 & Arcos & 688 & Lenha & 977 & Arvoredo \\
\hline 464 & Arcos & & & & \\
\hline
\end{tabular}

uma com clara conotação de epíteto geográfico (“Terra da Vera Cruz", linha 51) (Tab. 1).

Os termos usados por Caminha, quando referia-se a plantas, quer direta ou indiretamente, foram divididos em duas categorias: termos associados a plantas identificáveis botanicamente (19 termos) (Tab. 4) e termos associados a espé- cies não identificáveis (13 termos) (Tab. 3). Dentre as plantas identificáveis, cinco são exóticas (figo, trigo, castanha-portuguesa ou castanheiro, arroz e uva i.e., Ficus carica L., Triticum aestivum L., Castanea vesca Gaertn., Oryza sativa L., Vitis vinifera L. respetivamente). As demais seriam nativas da 
Tabela 2. Termos associados a plantas passíveis ou não de identificação botânica mencionados, de forma direta (31 termos) ou indireta (13 termos), na Carta de Pero Vaz de Caminha.

\begin{tabular}{|l|l|l|}
\hline Menções diretas: & & Menções indiretas: \\
\hline Ervas & Árvores & Arco (s) \\
Botelho & Castanheiros & Seta (s) [flecha] \\
Rabo-de-asno & Grãos vermelhos & Pão \\
Arvoredo & Madeira & Vinho \\
Lenha & Tábua & Almadias * \\
Figo & Palha & Tintura vermelha \\
Cabaça & Esteio & Tintura \\
Palmeira & Inhame & Tintura preta \\
Borracha & Semente & Cera \\
Espelho de pau & Mata & Cunha \\
Pau & Arroz & Pano \\
Palmas & Cana & Rede \\
Palmitos & Frutos & Cruz \\
Rama & Trigo & Tala \\
Fetos & Legumes & \\
Ouriços verdes & & \\
\hline
\end{tabular}

(* “as quais não são feitas como as que já vi; somente são três traves, atadas juntas"; linhas 367-369) [espécie de jangada, sem vela]

Nova Terra Descoberta. Os termos atribuídos a plantas, inclusos na categoria "identificáveis" foram agrupados em: identificáveis a nível de família, gênero e espécie.

A única espécie sobre cuja identificação não pairam dúvidas é o urucu ou urucum (Bixa orellana $\mathrm{L}$ ), descrita com admirável precisão por Caminha nas linhas 628 a 630 ("Traziam alguns deles uns ouriços verdes, de árvores, que, na cor, queriam parecer de castanheiros, embora mais e mais pequenos. E eram aqueles cheios duns grãos vermelhos pequenos, que, esmagados en-

Tabela 3. Termos associados a plantas não identificáveis citados na Carta de Pero Vaz de Caminha.

\begin{tabular}{lll}
\hline Lenha & Taboas & Tala \\
Pau & Rama & Borracha \\
[Espelho de] Pau & Semente & Esteio \\
Árvore (s) & Frutos & \\
Madeira & Cunha & \\
\hline
\end{tabular}

tre os dedos, faziam tintura vermelha, de que eles andavam tintos. E quanto mais se molhavam, tanto mais vermelhos ficavam“). Índios brasileiros fazem uso, ainda hoje, do mesmo processo citado por Caminha. A existência de cultivares de urucu foi recentemente identificada no Alto Xingu por Emmerich \& Emmerich (1993) que reconheceram a existência de duas cultivares, distintas pela coloração da semente e pela deiscência dos frutos. No chamado "urucu de homem", predomina o pigmento bixina e no "urucu de mulher" predomina pigmento orelina.

A palavra tintura aparece sete vezes (Tab. 1), sendo duas "tintura preta" (linhas 494 e 639), duas "tintura vermelha" (linhas 390 e 633) e três apenas "tintura (s)" (linhas 394, 623 e 783). Pode-se afirmar com bastante segurança que a tintura preta era obtida do jenipapeiro (Genipa americana L.). Diferentes autores concordam com esta identificação (Andrade-Lima, 1984; Pereira, 1999). 
Tabela 4. Termos passíveis de identificação botânica a nível de família, gênero ou espécie citados de forma direta ou indireta na Carta de Pero Vaz de Caminha (excluindo-se as referências a espécies exóticas, i.e., arroz, castanha, figo, uva, trigo)

\begin{tabular}{lll}
\hline Termo & Gênero/ Espécie & Família \\
\hline Palmito & Euterpe edulis Mart. & Arecaceae \\
Arcos pretos & Astrocarium airi Mart. & Arecaceae \\
Palmas & Attalea funifera Mart. & Arecaceae \\
Palha & $?$ & \\
Attalea funifera Mart. ? Arikuryroba & Arecaceae & \\
schizophylla (Mart.) Becc? & & \\
Palmeiras & Bixa orellana L. & Arecaceae \\
Ouriços verdes, Grãos vermelhos & Protium heptaphyllum March & Bixaceae \\
Cera ("confeição branda como cera") & Lagenaria vulgaris L. & Burseraceae \\
Cabaça & Alsophylla spp. ? Cyathea spp. ? & Cucurbitaceae \\
Fetos & Manihot spp (M. esculenta Crantz)? & Cyatheaceae \\
Inhame & Gynerium sagittatum Beauv. ? & Euphorbiaceae \\
Cana & Merostachys spp. ? & Poaceae \\
Rabo-de-asno & Halodule wrightii Asch., & \\
Tintura preta & H. emarginata Hartog & Potamogetonaceae \\
Ervas compridas ("Botelho") & Genipa americana L. & Rubiaceae \\
\hline
\end{tabular}

A referência "traziam cabaças de água" provavelmente diz respeito ao fruto de Lagenaria vulgaris L., planta originária do velho mundo, porém dispersa por todo o mundo tropical e subtropical. Admite-se sua existência na América do Sul desde tempos pré-colombianos (Andrade-Lima, 1984). A utilização dos frutos de Lagenaria vulgaris L. como vasilhame, das sementes de Bixa orellana L. e do exudado de Genipa americana L., como tinturas, atravessou o tempo, e as contendas resultantes do encontro de culturas ocorridos em terras brasileiras. Estas três espécies continuam sendo utilizadas com as mesmas finalidades descritas na Carta de Caminha. Existe, no entanto, outra possibilidade na identificação das tais "cabaças de água”. Trata-se da planta conhecida como coité ou cuité (Crescentia cujete L.) que também produz frutos com formato e utilização semelhantes aos da cabaça (L. vulgaris). Entretanto, sua utilização com a finalidade de transporte de água é menos provável que a da $L$. vulgaris, por ser muito mais frágil e quebradiça.

Palmas e palmitos são referidas cinco vezes (linhas 246, 529, 530 e 797). Andrade-Lima
(1984), considerando a região na qual aportou Cabral, atribuiu a referência a "moitas de palmas" (linha 246) a Attalea funifera Mart, a piassava, espécie frequiente nas proximidades das praias do sul-bahianas. O palmito é identificado pelo mesmo autor, com o que concordamos, como Euterpe edulis Mart., a conhecida juçara da Mata Atlântica.

A expressão "fetos muito grandes" pode ser atribuída a alguma espécie de Alsophila dentre aquelas que ocorrem nas matas costeiras sulbahianas.

O inhame referido por Caminha é motivo de controvérsia. Cortesão (1994) o identifica com espécies do gênero Dioscorea. AndradeLima (1984) parece concordar com a posição de Cortesão, acrescentando que espécies de Dioscorea são freqüentes, ainda hoje, nas florestas do litoral. Knathounian (1999), seguindo autores anteriores, atribui a referência ao gênero Manihot. Afirma que os portugueses conheciam a "raiz" longa e grossa de Dioscorea cayenensis, procedente da costa da África, especialmente do Golfo da Guiné, cujo nome "nham" foi aportuguesado para inhame e ex- 


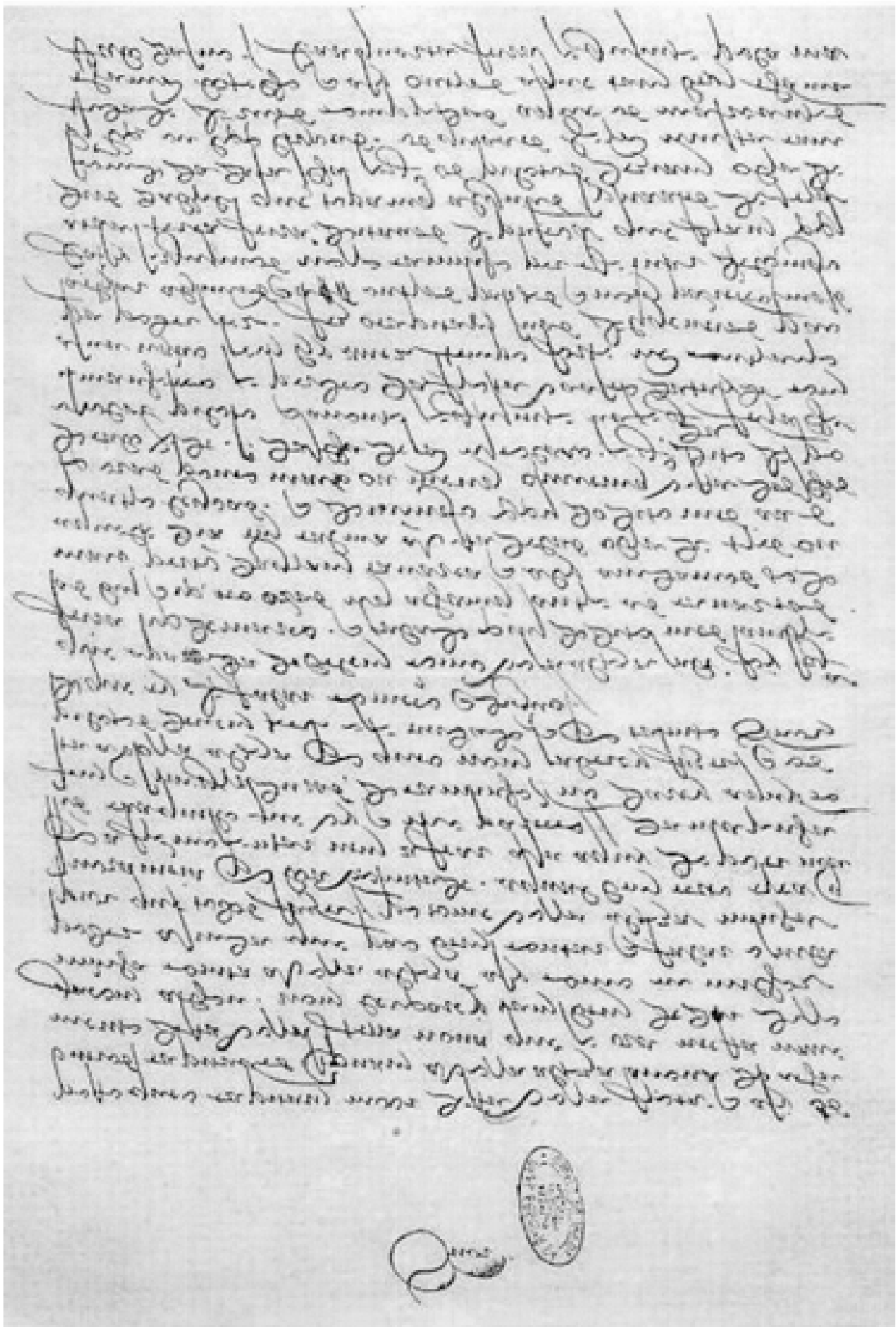

Figura 2. Reprodução de uma página da Carta escrita por Pero Vaz de Caminha, em 1500, ao rei de Portugal, D. Manoel I. 


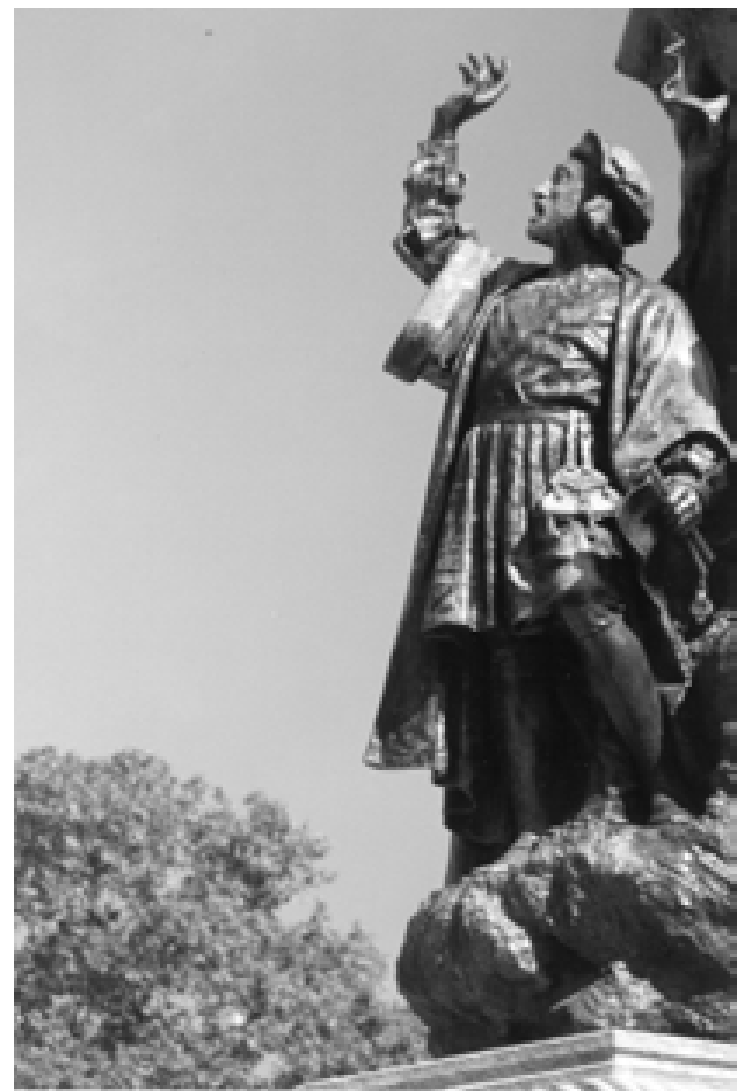

Figura 1. Fotografia da estátua de Pero Vaz de Caminha em monumento erguido em 1900, no Largo da Glória, Rio de Janeiro, RJ, em comemoração ao $4^{\circ}$ centenário do descobrimento do Brasil (foto S. Gonçalves).

tensivamente aplicado para várias espécies. Muito provavelmente Caminha chamou de inhame as raízes de Manihot esculenta Cranz, já cultivada pelos índios brasileiros. A "Relação" menciona um fato que parece corroborar com esta interpretação. No cap. II Mestre João diz que "alguns dos nossos", após um passeio pela aldeia dos autóctones, trouxeram de lá "huma raiz chamada inhame, que he o pão de que alli uzão"

Bueno (1998) citou "Botelhos" como algas da família Fucaceae (Fucus vesiculosus). Como esta espécie não ocorre nas costas brasileiras, aceita-se aqui a proposta de Andrade-Lima (1984) que os identificou como Sargassum sp. Densos bancos de Sargassum foram recentemente documentados no litoral dos estados do Rio de Janeiro e São Paulo (Széchy \& Paula, 2000), ensejando, inclusive, sua explotação comercial.

A identidade de "Rabos-de-asno" permanece enigmática. Levanta-se aqui a hipótese de que se trata de uma angiosperma marinha da família Potamogetonaceae. Estas plantas crescem sobre rochedos, mas podem desprender-se e flutar ao sabor das correntes (den Hartog, 1970). As espécies mais prováveis seriam Halodule wrightii Aschs., H. emarginatus Hartog, ambas encontradas no litoral nordestino, inclusive na praia Coroa Vermelha, Santa Cruz de Cabrália (Oliveira et al. 1983). Dentre outras espécies encontradas ao longo da costa brasileira destacam-se Ruppia maritima L. e Halophila baillonii Aschers. (Oliveira et al., 1983).

O termo "palha" (linha 653) pode referir-se tanto a folha de palmeiras (Arecaceae) quanto de gramíneas (Poaceae). Andrade-Lima levanta várias possibilidades sobre a identidade das palmeiras mencionadas como palha. Dentre elas cita Attalea funifera Mart. e Arikuryroba schizophylla (Mart.) Becc.

Das 14 referências indiretas, duas (pão e vinho obtidos de $T$. aestivum e $V$. vinifera, respectivamente) referem-se a plantas européias. As palavras "arco" (s), "seta" (s), "almadias", "cruz", etc. referem-se a objetos confeccionados com partes retiradas de plantas lenhosas. As "setas" (flechas) são sobejamente mencionadas no texto. Segundo Andrade Lima (1984) seriam confeccionadas de materiais diversos, de acordo com a finalidade a que se destinassem. Em sua confecção, entrariam, pois, materiais tais como madeira (variadas), lascas de taquara (Merostachys spp.) e eixo da sinflorescência da canabrava (Gynerium sagittatum $\mathrm{P}$. Beauv.). Os arcos, com o qualificativo pretos, que lhes é dado, teriam sido feitos, como ainda hoje o são, da estipe de uma palmeira. Andrade Lima (1984) considerou que os arcos seriam feitos das estipes de espécies de Astrocaryum, entre as quais possivelmente A. airi Mart. 
Para Andrade-Lima (1984) as "canas aparadas" (linhas 724-725) seriam confeccionadas com "lascas de taquaras". Concordamos com a sugestão de que seriam confeccionadas com fragmentos retiradas dos entrenós do colmo de espécies de Merostachys spp. No entanto, diversos outros gêneros de gramíneas bambusóides, ocorrentes na Mata Atlântica poderiam, igualmente, fornecer a matéria prima para sua fabricação. São eles: Alvimia Soderstrom \& Londoño, Athroostachys Benth., Atractantha McClure, Aulonemia Goudot, Chusquea Kunth, Eremocaulon Soderstrom \& Londoño, Guadua Kunth e Merostachys Spreng. (Burman \& Filgueiras 1993; Judziewicz et al. 1999).

A frase "confeição branda como de cera, e não o era" (linhas 155 e 156) é interpretada por Andrade-Lima (1974) como a resina do breu ou almécega, retirada de árvores e arbustos do gênero Protium (Burseraceae), sendo $P$. heptaphyllum Mart. a espécie mais comumente encontrada na Mata Atlântica.

Os termos "pano" (s) e "rede" também se referem a objetos confeccionados com partes retiradas de plantas. Tais plantas permanecem não identificadas. Entretanto, a "Relação" menciona fato significativo neste contexto. No cap. II o autor diz que a nova terra é muito abundante em "milho, inhame e algodão". Se algodão era abundante naquele época, provavelmente os tricomas que revestem suas sementes fossem utilizados nas confecção de "panos" (linhas 502, 505, 948). Gossypium bardadense L., o algodão-mocó do nordeste brasileiro é o candidato natural, pois trata-se de uma espécie nativa naquela região.

O texto da "Relação" contém ainda alguns enigmas vegetais que carecem de explicação. Dentre eles citam-se a indicação de que os portugueses trouxeram de uma incursão à aldeia dos tupiniquins "algum arroz" e que havia abundância de "milho" na terra. Como Caminha não cita nenhuma dessas plantas, não se especula aqui sobre a identidade de tais referências.
O significado dos termos "espelho de pau" (linha 274) e "borracha" (linha 275) no contexto da Carta foi astutamente desvendado por Andrade-Lima (1984) e não carece de maiores explicações. Os termos "cunha" (linha 696) e "tala" (linha 697), ambos referências indiretas a partes de plantas, estão inclusos no grupo das não identificáveis.

O local onde se celebrou a Primeira Missa é descrito por Caminha (linhas 326-329) como "um grande ilhéu, que na baía está e que na baixa-mar fica mui vazio. Porém é de todas as partes cercado de água, que não pode ninguém ir a ele sem barco ou a nado". A descrição é complementada adiante (linhas 407-409): "Neste ilhéu, aonde fomos ouvir missa e pregação, espraia muito a água, e descobre muita areia e muito cascalho". Caminha descreve assim um local desolado, o que contrasta com a luxuriante vegetação, característica da Mata Atlântica, mostrado no célebre quadro a óleo, "Primeira Missa no Brasil”, criação admirável do pintor Victor Meirelles.

A presença de uma cruz durante a celebração da Primeira Missa, também não tem respaldo no texto da Carta. A cruz foi confeccionada por dois carpinteiros (linhas 688-689) e "chantada" (linha 874) dias depois, por ocasião de uma segunda missa, também dita pelo "padre frei Henrique" (linhas 876-877).

\section{Referências bibliográficas}

Andrade-Lima, D. de. 1984. A botânica da Carta de Pero Vaz de Caminha. Rodriguésia 36: 5-8.

Borgmeier, 1961. A história da Flora Fluminensis de Frei Velloso. Publ. Arq. Nac. 48: 3-21.

Braga, R. 1981. Pero Vaz De Caminha - Carta a El Rey D. Manoel. Versão Moderna de Rubem Braga; ilustrações de Carybé. Record, Rio de Janeiro. Edição de 1981.

Bueno, E. 1998. A viagem do descobrimento. Rio de Janeiro, Objetiva (Coleção Terra Brasilis: 1).

Burman, A. G. \& Filgueiras, T. S. 1993. A review of the woody bamboo genera of Brazil (Gramineae: Bambusoideae: Bambuseae). Thaiszia 3: 53-88. 
Carauta, J.P.P. 1967. Naturalistas na Guanabara. Quatro séculos de impressões. Boletim Geográfico 200: 3-32.

Cortesão, J. 1994. A expedição de Pedro Álvares Cabral e o descobrimento do Brasil. Lisboa. Imprensa Nacional-Casa da Moeda. (Jaime Cortesão, Obras Completas, vol. 6) [Reimpresão do livro publicado em 1922, em Lisboa, pela Livraria Aillaud \& Bertrand].

Cortesão, J. 1943. A Carta de Pero Vaz de Caminha. Ed. Livros de Portugal. Rio de Janeiro.

den Hartog, C. 1970. The seagrasses of the world. North Holland Publ. Co., Amsterdam.

Emmerich, M. \& Emmerich, C. 1993. Urucu (Bixa orellana L.) no Alto Xingu. Bradea 6: 232-233.

Judziewicz, E., Clark, L. G., Londoño, X. \& Stern, M. J. 1999. American bamboos. Washington, Smithsonian Institution Press.

Khathounian, C.A. 1999. Carás, inhames e assemelhados. Boletim Agroecológico 13: 4-5.

Margulis, L., Schwartz, K. 1999. Five kingdoms: An illustrated guide to the phyla of life on earth. $3^{\text {rd }}$ ed. New York. W.H.Freeman and Co.

Moulin, D. de, Maule, A.F., Andrade Lima, D., Rahm, K. E. et Pedersen, T.M. 1986. O Herbário de Georg Marggraf. Vol 1,2. Ministério da Cultura, SPHAN/ Pro-Memória, Fundarpe, Brasília.

Oliveira, E. C. de, Pirani, J.R. et Giulietti, A. M. 1983. The Brazilian seagrasses. Aquatic Botany 16: 251-267.

Peixoto, A.L. 1999. Brazilian botany on the threshold of the 21th century: Looking through the scientific collections. Ciência e Cultura 51 (5/6): 349-362.

Pereira, P.R. 1999. Os três únicos testemunhos do descobrimento do Brasil. 2a . ed. revisada. Ed. Nova Aguilar S.A. Rio de Janeiro. 107p.

Silva, M.B.N. 1995. A história natural do Brasil antes das viagens do príncipe Maxmiliano. Oceanos 24: 12-24.

Simões, H. C. 1999. As cartas do Brasil. Ilhéus, Editus.

Széchy, M. T. de \& Paula, E. J. de. 2000. Padrões estruturais quantitativos de bancos de Sargassum (Phaephyta, Fucales) do litoral dos estados do Rio de Janeiro e São Paulo. Brasil. Revta brasil. Bot. 23: $121-132$. 